\title{
Tourismuslehre - Ein Grundriss
}

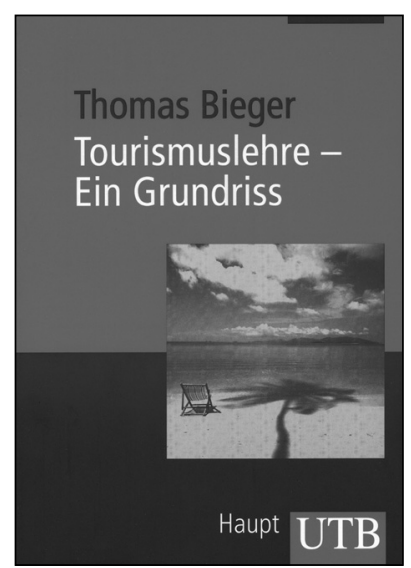

«Uni-Taschenbücher - mittlere Reihe» Band 2536. 349 Seiten, 135 Grafiken und Tabellen, kartoniert, EUR 19.90/CHF 34.90

ISBN 3-8252-2536-4

Tourismus wird in diesem Lehrbuch interdisziplinär betrachtet, als Wirtschaftsbereich genauso wie als gesellschaftliches Phänomen und unter ökologischem Blickwinkel. Das Buch beruht auf systemtheoretischen Ansätzen, wobei die folgenden Subsysteme gesondert behandelt werden: Nachfrage, Destination, Reisemittlung und Verkehr. Das Buch weist so eine leicht nachvollziehbare didaktische Struktur auf. Klare Begriffsdefinitionen, einprägsame Darstellungen und durchgehende Bezüge zum systemischen Grundmodell erleichtern das Verständnis. Handlungsorientiert werden Planungs- und Entscheidungsansätze aufgearbeitet, jeder Teil ist anhand einer Fallstudie illustriert.

Thomas Bieger, 1961, Prof. Dr. rer. pol., ist Ordinarius für BWL mit besonderer Berücksichtigung der Tourismuswirtschaft und geschäftsführender Direktor des Instituts für öffentliche Dienstleistungen und Tourismus der Universität St. Gallen.

Seit 1998 Generalsekretär der International Association of Scientific Experts in Tourism (AIEST) und seit 2000 Delegierter des Rektors für internationale Austauschprogramme.

Publikations-, Forschungs-, Beratungs- und Unterrichtstätigkeit u.a. an verschiedenen Hochschulen/Universitäten (z. B. Gastprofessuren Universität Innsbruck und Wirtschaftsuniversität Wien) mit Schwergewicht Dienstleistungsmanagement und Netzmanagement sowie Destinationsmanagement und Standortmanagement. Wichtige Veröffentlichungen: Destinationsmanagement, fünfte Auflage 2001; Dienstleistungsmanagement, zweite Auflage 2000; Zukünftige Geschäftsmodelle, 2002; Finanzierung im Tourismus, 1999.

\section{Haupt Verlag}

Falkenplatz 14, CH-3001 Bern, Telefon ++41 (0)31 30909 00, Fax ++41 (0)31 30909 90, verlag@haupt.ch, www.haupt.ch

\section{Bestellschein}

Bitte bestellen Sie bei der Haupt Buchhandlung (Fax 03130909 10) oder bei jeder anderen Buchhandlung.

Ex. Thomas Bieger

Tourismuslehre - Ein Grundriss

«Uni-Taschenbücher - mittlere Reihe» Band 2536.

349 Seiten, 135 Grafiken und Tabellen, kartoniert,

EUR 19.90/CHF 34.90 (zzgl. Versandkosten)

ISBN 3-8252-2536-4

Name/Norname:

Adresse:

E-Mail: 